\title{
Green Synthesis of Copper Oxide Nanoparticles Mediated by Aqueous Leaf Extracts of Leucas aspera and Morinda tinctoria
}

\author{
Ramesh Radhakrishnan 1,2,*(D), Faize Liakath Ali Khan ${ }^{2}$, Aravinthraj Muthu 1(D), Anitha Manokaran ${ }^{1}$, \\ John Sundaram Savarenathan 1, Kaviyarasu Kasinathan ${ }^{3,4}$ \\ 1 Department of Physics, Sacred Heart College (Autonomous), Tirupattur,635 601, Tamil Nadu, India \\ 2 Department of Physics, Islamiah College (Autonomous), Vaniyambadi, 635 752, Tamil Nadu, India \\ 3 UNESCO-UNISA Africa Chair in Nanosciences/Nanotechnology Laboratories, College of Graduate Studies, University \\ of South Africa (UNISA), Muckleneuk Ridge, PO Box 392, Pretoria, South Africa \\ 4 Nanosciences African Network (NANOAFNET), Materials Research Group (MRG), iThemba LABS-National Research \\ Foundation (NRF), 1 Old Faure Road, 7129, PO Box 722, Somerset West, Western Cape Province, South Africa \\ * Correspondence: rramesh@shctpt.edu;
}

Received: 18.01.2021; Revised: 25.03.2021; Accepted: 3.04.2021; Published: 8.05.2021

\begin{abstract}
Copper oxide nanoparticles were successfully synthesized using the aqueous leaf extracts of Leucas aspera and Morinda tinctoria plant material with copper sulfate $\left(\mathrm{CuSO}_{4} .5 \mathrm{H}_{2} \mathrm{O}\right)$ as the precursor. The crystalline nature and morphology of the synthesized sample were identified using XRD and SEM analytical instrumentation and found that the crystal was in the monoclinic phase, and the average particle size was estimated as $30.32 \mathrm{~nm}$ and $18.72 \mathrm{~nm}$ for both the samples. The functional groups were identified using FTIR spectroscopy, and the strong absorption peak at $620 \mathrm{~cm}^{-1}$ and $615 \mathrm{~cm}^{-1}$ confirms the presence of $\mathrm{Cu}-\mathrm{O}$ vibration. The optical bandgap of the plant leaf extract mediated $\mathrm{CuO}$ particles was calculated based on the results obtained from UV-Vis spectroscopy and found that the value of the energy gap is $5.6 \mathrm{eV}$ and $3.16 \mathrm{eV}$. The antibacterial activity of plant samples was carried out by the disc diffusion method. The test compounds' concentrations were taken in DMSO and used in the concentration of $500 \mu \mathrm{g}$ and $1000 \mu \mathrm{g} /$ disc. The zone of inhibition formed by the prepared $\mathrm{CuO}$ nanoparticles was good and compared with Amikacin's standard value. The study reports the plant leaf extract mediated $\mathrm{CuO}$ nanoparticles might find suitable application in the field of nanotechnology.
\end{abstract}

Keywords: Leucas aspera; Morinda tinctoria; green synthesis; copper oxide; antibacterial.

(C) 2021 by the authors. This article is an open-access article distributed under the terms and conditions of the Creative Commons Attribution (CC BY) license (https://creativecommons.org/licenses/by/4.0/).

\section{Introduction}

Among metal oxides, copper oxide has attained more attraction in the last few decades due to its characteristic properties such as high-temperature superconductivity, electron correlation effects, spin dynamics, etc. CuO NPs have been used in various fields, including industrial engineering, agriculture, and technical fields [1]. Recently the field of agriculture focused on the impact of certain minor elements on the economy of plants. Bionanotechnology utilizes biological principles and chemical approaches to yield nano-sized particles with specific functions. The morphology and size effect contribute a maximum for developing new tools and ideas for the technical approach in various fields [2]. For instance, the fabrication of metal oxide nanoparticles like silver and gold finds some difficulties and is cost-effective, whereas synthesizing $\mathrm{CuO}$ NPs is eco-friendly and finds useful properties and is achievable at 
lower costs than silver and gold. Moreover, the specific properties like catalytic, optical, electrical, antibacterial, and antifungal applications exhibited by $\mathrm{CuO}$ NPs are excellent compared to other metals. Biosynthesis of CuO NPs by plant leaf extracts such as Euphorbia nivulia and Nerium oleander has been reported [3], and plants' potential as biological materials for the synthesis of CuO NPs is yet to be focused and explored thoroughly. Leucas aspera is commonly known as Thumbai (in Tamil) and is distributed throughout India from the Himalayas down to Ceylon. The plant is used traditionally as an antipyretic and insecticide [4]. The leaves are useful in chronic rheumatism, psoriasis, and other chronic skin eruptions. The steam is used for inhalation in conditions like nasal congestion, cough, cold, fever, headaches, etc. The plant is reported to contain various phytochemicals such as oleanolic acid, ursolic acid, $\alpha$-sitosterol, $\beta$-sitosterol, reducing sugars, diterpenes, glycosides, (-)-isololiolide, linifolioside, nicotine, macelignan, acacetin, apigenin, myristargenol $\mathrm{B}$, machilin $\mathrm{C}$, and (-)-chicanine. In addition to the above-said compounds, steroids, triterpenes, phenols, flavonoids, tannins, and long-chain aliphatic compounds were also reported [5]. Morinda tinctoria is another plant material used in this study; it is locally known as "Togaru" and commonly known as Indian mulberry or aal or nunaa in India. The plant is well known for its therapeutic use in traditional systems of medicine like Ayurveda and Siddha. The leaves are used internally as a tonic and febrifuge. There are reports which showed antibacterial and antifungal activities [6]. The ashes of Morinda tinctoria leaves were also reported to act as bioabsorbents in controlling ammonia pollution in wastewaters [7].

In this study, we report the green synthesis of Copper oxide $(\mathrm{CuO})$ NPs mediated by aqueous leaf extracts of Leucas aspera and Morinda tinctoria plant. The study's objective is to compare the effects of the bio reducing compounds present in the leaf extracts in forming the $\mathrm{CuO}$ nanoparticles. The same procedure was adopted for both the plant leaf extracts mediated synthesis of $\mathrm{CuO}$ nanoparticles with copper sulfate as the precursor material. The synthesized $\mathrm{CuO}$ NPs were characterized using various analytical techniques like XRD, FTIR, SEM, UVVis, and antibacterial studies.

\section{Materials and Methods}

\subsection{Preparation of leaf extracts}

Experimental leaves of Leucas aspera and Morinda tinctoria were collected from the rural area around Tirupattur district, Tamil Nadu, India. The extract was prepared separately for each experimental leaf with the same procedure [8-9]. The extract was prepared by using fresh Leucas aspera leaves. The leaves were washed thoroughly in running water for few minutes and then washed with deionized water. About $25 \mathrm{~g}$ of finely cut Leucas aspera leaves were taken and poured in to $100 \mathrm{ml}$ of deionized water and heated until the water attains $80{ }^{\circ} \mathrm{C}$ for $20 \mathrm{~min}$. The solution appeared as a light pale green color, and the extract was filtered through a sterile serene cloth and refiltered through Whatman No.1 filter paper to get a clear solution. The filtrate was collected and stored at $4{ }^{\circ} \mathrm{C}$ for further use. The same procedure was adopted for the preparation of Morinda tinctoria leaf extract preparation.

\subsection{Synthesis of copper oxide nanoparticles.}

All the chemical reagents are of analytical grade and used without further purification. Nanoparticles of $\mathrm{CuO}$ were prepared using the Leucas aspera and Morinda tinctoria leaf extracts as a bio-reducing agent. $\mathrm{CuSO}_{4} .5 \mathrm{H}_{2} \mathrm{O}$ was used as the precursor, and about $0.37 \mathrm{~g}$ was 
dissolved in $75 \mathrm{ml}$ of deionized water and stirred well in the magnetic stirrer [10-12]. About $25 \mathrm{ml}$ of fresh leaf extract of Leucas aspera was added into the prepared copper sulfate solution. The solution color changed from blue to pale yellowish-green, and on vigorous stirring, the solution changed its color to dark brownish-green [13-17]. The final solution was centrifuged well for $20 \mathrm{~min}$ at $10,000 \mathrm{rpm}$, and the solution is multi-washed by double distilled water and was poured into the Petri dish and kept in the air oven at $100{ }^{\circ} \mathrm{C}$ [18] for 2 hours for further study. A similar synthesis procedure was adopted for the Morinda tinctoria mediated $\mathrm{CuO}$ nanoparticles.

\section{Results and Discussion}

\subsection{Powder X-ray diffraction analysis}

The specimen was analyzed using the XRD technique to investigate the structure and nature of the synthesized $\mathrm{CuO}$ nanoparticles mediated by Leucas aspera and Morinda tinctoria leaf extracts. The recorded XRD pattern of the $\mathrm{CuO}$ is shown in Figure 1(a-b). The $2 \theta$ value ranging from $20^{\circ}$ to $90^{\circ}$ with intense peaks specific for Copper Oxide nanoparticles at $25.9^{\circ}$, $44.34^{\circ}, 64.5^{\circ}$, and $77.7^{\circ}$ were observed [19]. These peaks correspond to (200), (111), (200),(202), (220), and (311) planes, indicating that the particles are crystalline. The sharp bands of Bragg's peak authenticate that the particles are in the nano regime [20] and are stabilized by the bio reducing agents present in the leaf extracts of Leucas aspera and Morinda tinctoria. The planes are in good agreement with standard diffraction data (JCPDS-80-1916) and confirming the formation of a monoclinic crystalline structure [21]. The average particle size was estimated using Debye-Scherer Equation. The average particle size was found to be $30.32 \mathrm{~nm}$ and $18.72 \mathrm{~nm}$, respectively.

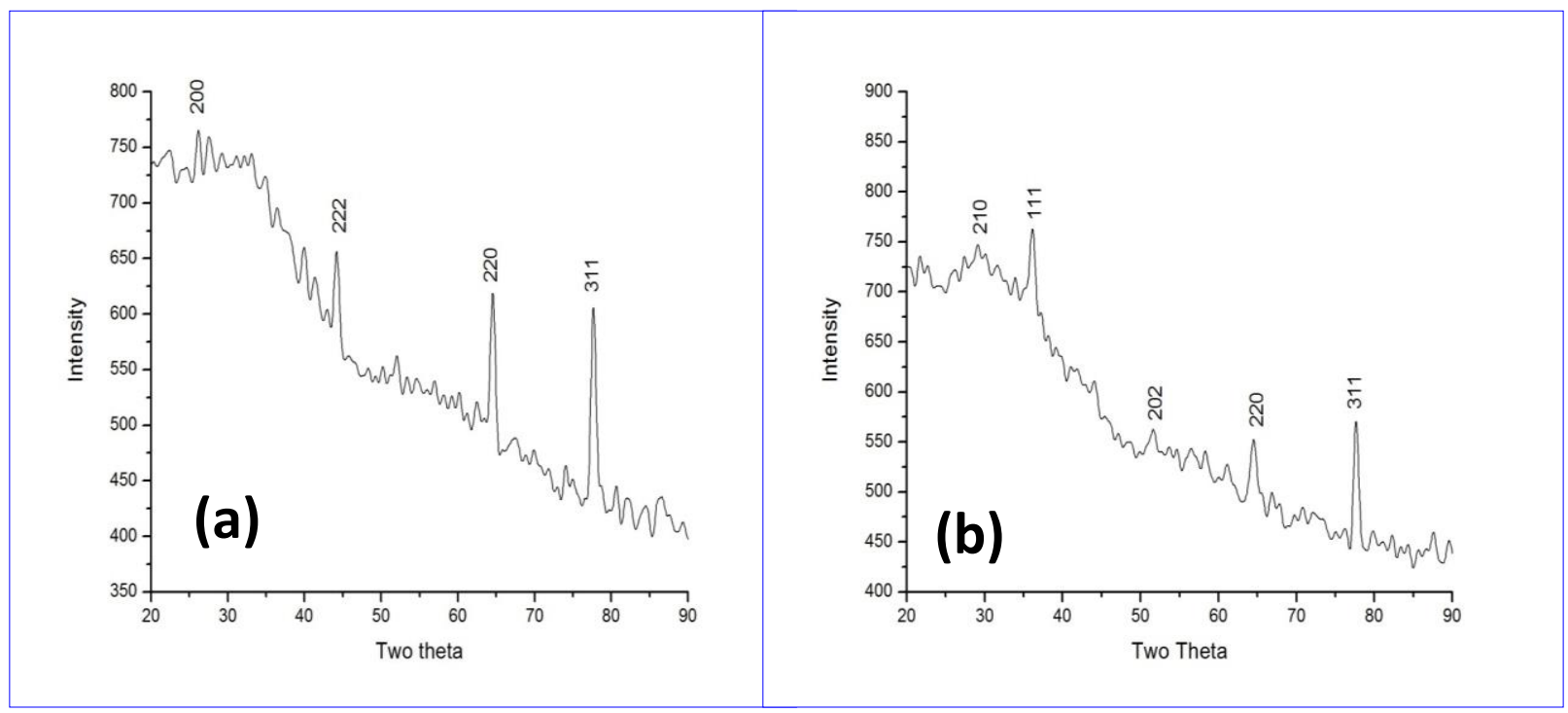

Figure 1. XRD Pattern of (a) Leucas aspera mediated $\mathrm{CuO}$; (b) Morinda tinctoria mediated CuO.

\subsection{FTIR analysis.}

FTIR analysis was carried out to identify the functional groups, and the recorded spectrum is shown in Figure 2(a-b). About 16 absorption peaks were observed for both leaf extracts mediated $\mathrm{CuO}$ samples. It shows the interaction sites of the bio-reducing compounds of the leaf in the formation of bonding. The peaks at $3956 \mathrm{~cm}^{-1}, 3908 \mathrm{~cm}^{-1}$, and $3758.65 \mathrm{~cm}^{-1}$ are due to $\mathrm{OH}$ bending and stretching of water molecules [22]; the peak at $3402.31 \mathrm{~cm}^{-1}$ is due 
to $\mathrm{OH}$ stretching of hydrogen-bonded alcohols and phenol compounds [23]. The peaks around $1627 \mathrm{~cm}^{-1}$ and $1630 \mathrm{~cm}^{-1}$ are due to unsaturated nitrogen, tannins, and alkaloids present in the leaf extracts [24]. The absorption peaks $2926.35 \mathrm{~cm}^{-1}$ and $2925 \mathrm{~cm}^{-1}$ were assigned to $-\mathrm{CH}_{2}$ stretching mode in alkanes, and the peak at $2340.78 \mathrm{~cm}^{-1}$ assigned to $-\mathrm{N}=\mathrm{C}=\mathrm{O}$ stretching. The peak at $136 \mathrm{~cm}^{-1}$ and $1100 \mathrm{~cm}^{-1}$ shows $\mathrm{C}-\mathrm{N}$ stretching of the aromatic amino group. A strong absorption peak at $1069 \mathrm{~cm}^{-1}$ is due to the aliphatic fluoro compounds [25]. The peak at 620.58 $\mathrm{cm}^{-1}$ and $615.45 \mathrm{~cm}^{-1}$ in both the samples confirms the formation of the metal oxide bond $\mathrm{Cu}-$ $\mathrm{O}$.

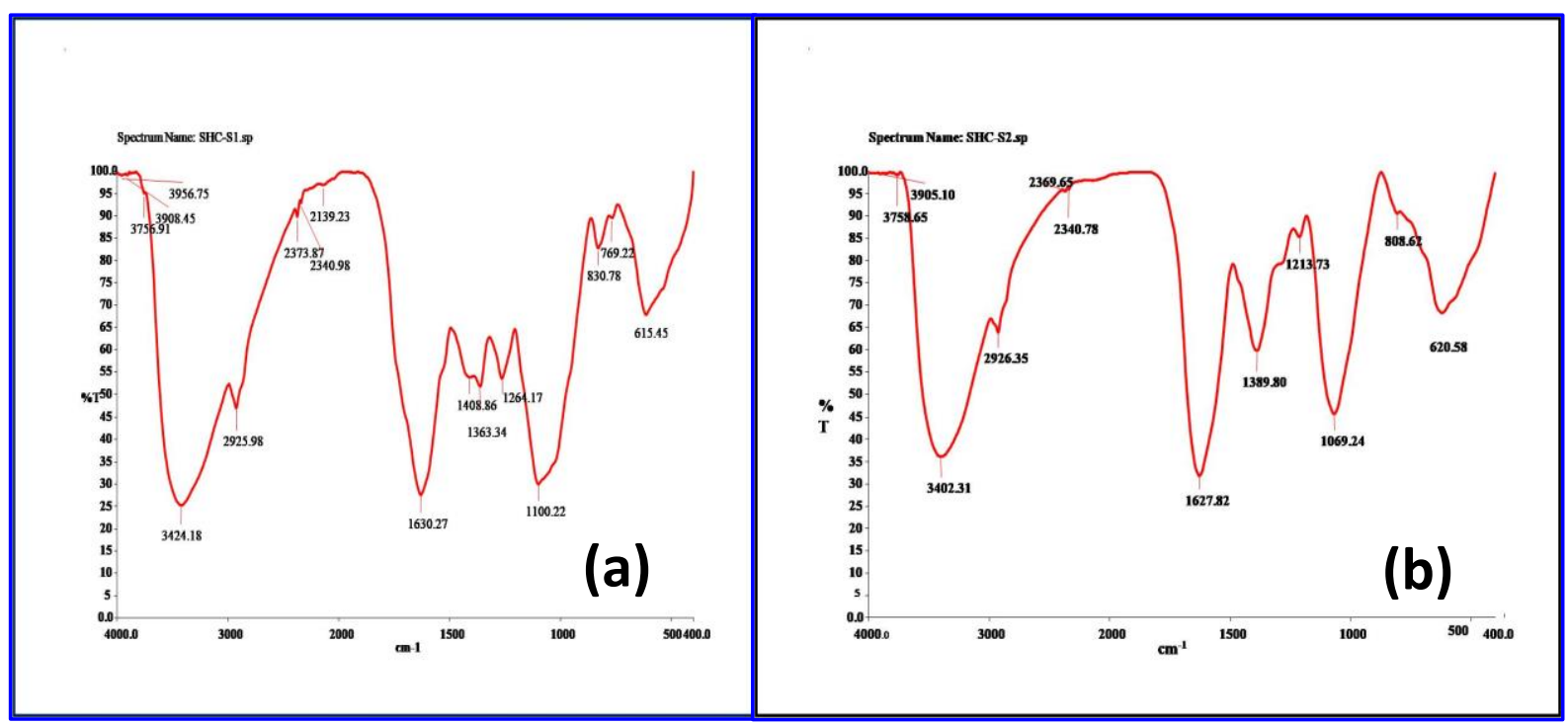

Figure 2. FTIR Spectrum of (a) Leucas aspera mediated CuO; (b) Morinda tinctoria mediated CuO.

\subsection{UV-visible spectroscopic analysis.}

The result obtained from UV-Visible spectroscopy analysis of both the leaf extract mediated $\mathrm{CuO}$ samples is given in Figure 3(a-b). The $\mathrm{CuO}$ NPs formation was confirmed from the peak at $319 \mathrm{~nm}$ in Leucas aspera leaf extract and $412 \mathrm{~nm}$ for the Morinda tinctoria leaf extract sample [26].

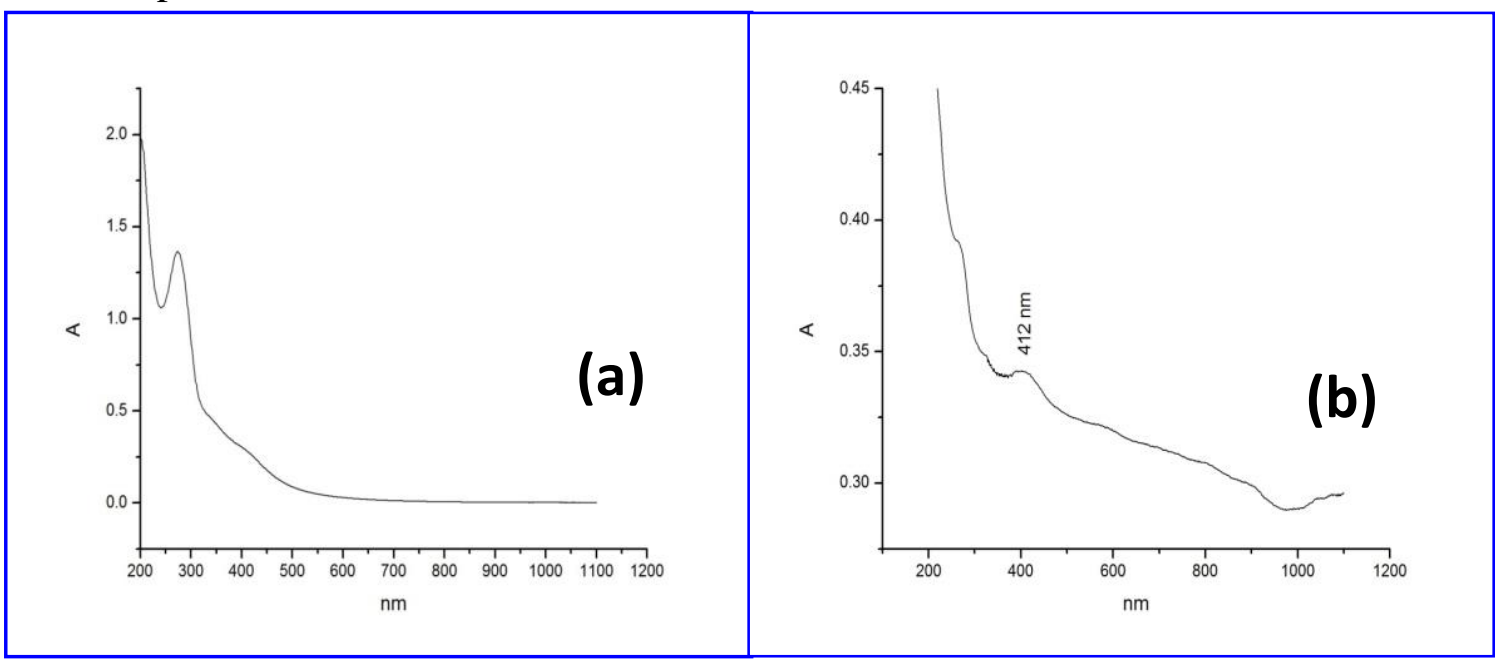

Figure 3. UV-Vis Spectrum of (a) Leucas aspera mediated CuO; (b) Morinda tinctoria mediated CuO.

These results agree with the reported investigations on plant leaf extract mediated $\mathrm{CuO}$ nanoparticles. It is attributed to the reason that the bio-reducing compounds present in the various plants modify the range of absorption and the optical activity in the UV-Vis region. Copper SPR effects decrease with time because of the oxidation of the synthesized copper [27]. 
The peak value was gradually decreased with the increase in particle size in the Leucas aspera leaf extract sample. The bandgap for the copper oxide nanoparticles is found to be $5.6 \mathrm{eV}$ and $3.16 \mathrm{eV}$.

\subsection{Morphological analysis}

The morphological nature of the Leucas aspera and Morinda tinctoria leaf extract mediated $\mathrm{CuO}$ nanoparticles were analyzed using SEM analytical technique and is shown in Figure 4(a-b). The obtained results show that the particles were agglomerated, overlapped, and distributed non-homogeneously [28-32]. It may be due to the interaction of the bioactive and phytochemical compounds present in the leaf extracts. The SEM image shows some small spherical shape in the Leucas aspera leaf extract mediated sample and small cubical shapes in the case of the Morinda tinctoria mediated sample [33]. The variations in the sample's morphology prepared by the sampling procedure and exhibiting the different morphology and shape indicate that the formation of nanoparticles is dependent [34] on nature and the chemical compound present in the reducing/ capping agent of the plant materials taken for the investigation.

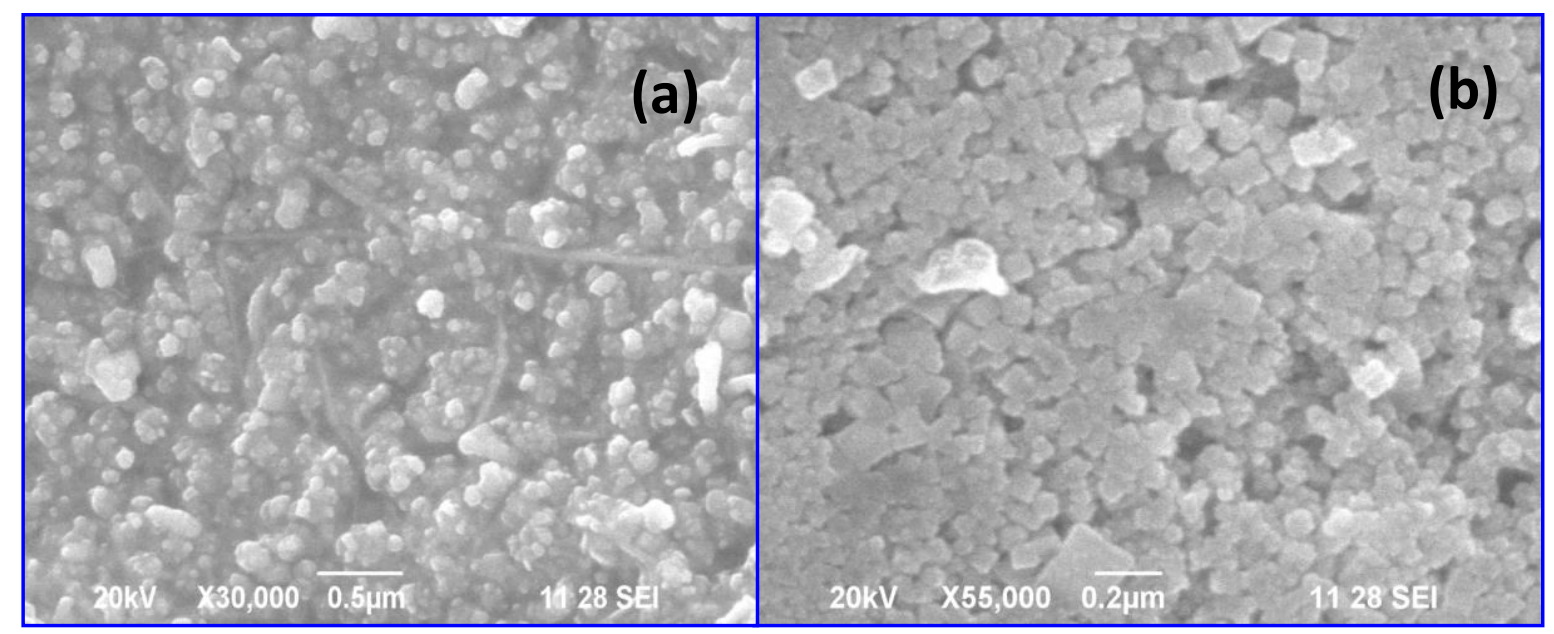

Figure 4. SEM image of (a) Leucas aspera mediated CuO; (b) Morinda tinctoria mediated CuO.

\subsection{Antibacterial activity of prepared $\mathrm{CuO}$ nanoparticles.}

The antibacterial activity of plant samples was carried out by the disc diffusion method and is shown in Figure 5(a-b). The test compounds' concentrations were taken in DMSO and used in the concentration of $500 \mu \mathrm{g}$ and $1000 \mu \mathrm{g}$ g/disc. The target microorganisms were cultured in Mueller-Hinton broth (MHB). After $24 \mathrm{~h}$, the suspensions were adjusted to standard sub-culture dilution. The Petri dishes containing Muller Hinton Agar (MHA) medium were cultured with diluted bacterial strain. A disc made of Whatman No.1, diameter $6 \mathrm{~mm}$, was presterilized and was maintained in an aseptic chamber. Each concentration was injected into the sterile disc papers. Then the prepared discs were placed on the culture medium. Standard drug amikacin $(30 \mu \mathrm{g})$ was used as a positive reference [35] standard to determine the sensitivity of each microbial species tested. Then the inoculated plates were incubated at $37^{\circ} \mathrm{C}$ for $24 \mathrm{~h}$. The clear zone diameter around the disc was measured and expressed in millimeters as its antimicrobial activity. Both samples were screened for in vitro antibacterial activity against Escherichia coli, Staphylococcus aureus, Pseudomonas aeruginosa, and Bacillus subtilis by disc diffusion technique compared with standard drug Amikacin $(30 \mu \mathrm{g})$ [36]. The details of 
the organism used for the study and the inhibition zone for the Leucas aspera and Morinda tinctoria sample were calculated in mm and given in Tables (1-3).

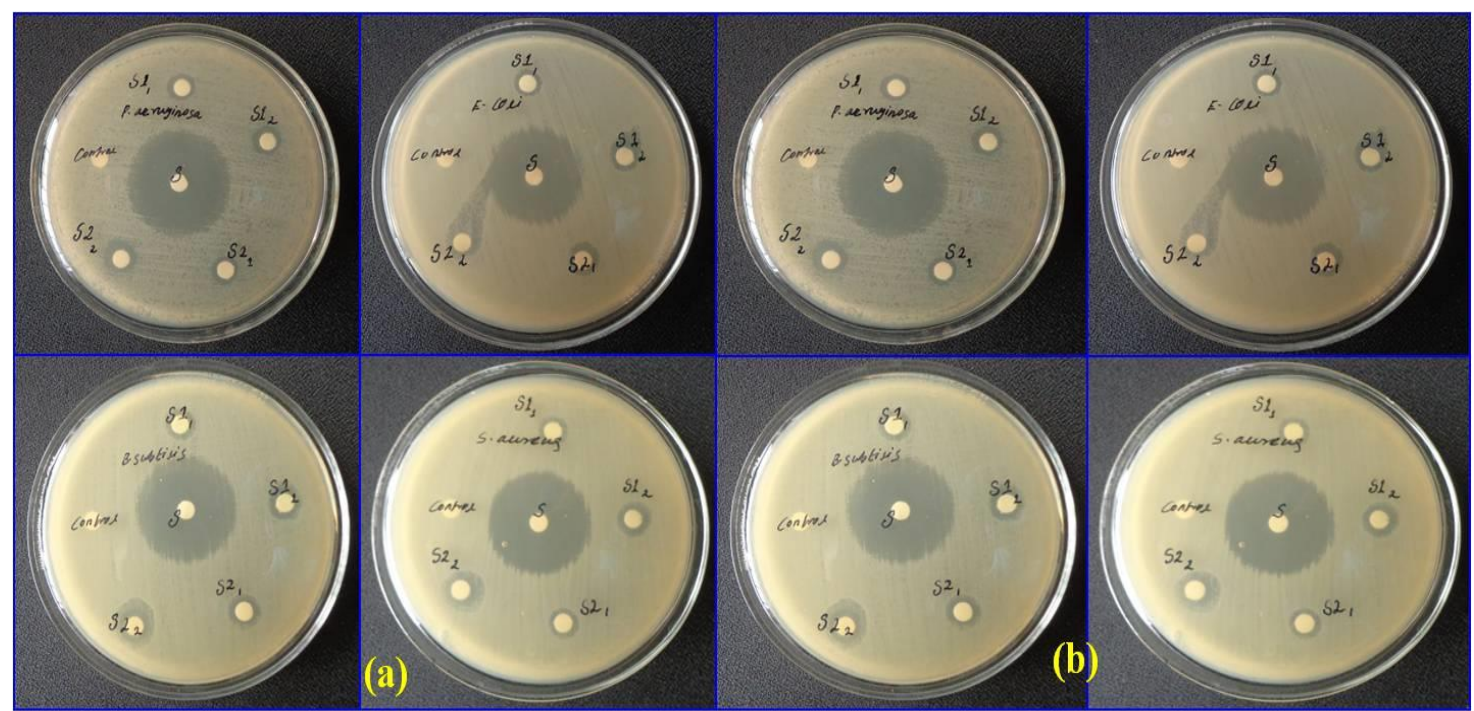

Figure 5. Antibacterial activity of (a) Leucas aspera mediated CuO; (b) Morinda tinctoria mediated CuO.

Table 1. Details of the microorganisms used for the study.

\begin{tabular}{c|c|c} 
Grams strain & Name of the organism & Std Code \\
\hline Gram-negative & Pseudomonas aeruginosa & (ATCC-2853) \\
\hline Gram-negative & Escherichia coli & (ATCC-25922) \\
\hline Gram-positive bacterium & Bacillus subtilis & (ATCC-6051) \\
\hline Gram-positive bacterium & Staphylococcus aureus & (ATCC-9144)
\end{tabular}

Table. 2. Antibacterial zone of inhibition for Leucas aspera leaf extract mediated CuO nanoparticles.

\begin{tabular}{|c|c|c|c|c|c|c|c|c|}
\hline Sample & \multicolumn{8}{|c|}{ Zone of Inhibition (mm) } \\
\hline \multirow{3}{*}{ S1- Leucas aspera } & \multicolumn{2}{|c|}{ S. aureus } & \multicolumn{2}{|c|}{ B. subtilis } & \multicolumn{2}{|c|}{ E. coli } & \multicolumn{2}{|c|}{ P. aeruginosa } \\
\hline & $500 \mu \mathrm{g}$ & $1000 \mu \mathrm{g}$ & $500 \mu \mathrm{g}$ & $1000 \mu \mathrm{g}$ & $500 \mu \mathrm{g}$ & $1000 \mu \mathrm{g}$ & $500 \mu \mathrm{g}$ & $1000 \mu \mathrm{g}$ \\
\hline & 10 & 12 & 14 & 16 & 10 & 12 & 10 & 10 \\
\hline Amikacin $(30 \mu g)$ & \multicolumn{2}{|c|}{36} & \multicolumn{2}{|c|}{36} & \multicolumn{2}{|c|}{34} & \multicolumn{2}{|c|}{36} \\
\hline
\end{tabular}

Table 3. Antibacterial zone of inhibition for Morinda tinctoria leaf extract mediated CuO nanoparticles. Sample Zone of Inhibition (mm)

\begin{tabular}{c|c|c|c|c|c|c|c|c}
\hline \multirow{2}{*}{ S2-Morinda tinctoria } & \multicolumn{2}{|c|}{ S. aureus } & \multicolumn{2}{c|}{ B. subtilis } & \multicolumn{2}{c|}{ E. coli } & \multicolumn{2}{c}{ P. aeruginosa } \\
\cline { 2 - 9 } & $500 \mu \mathrm{g}$ & $1000 \mu \mathrm{g}$ & $500 \mu \mathrm{g}$ & $1000 \mu \mathrm{g}$ & $500 \mu \mathrm{g}$ & $1000 \mu \mathrm{g}$ & $500 \mu \mathrm{g}$ & $1000 \mu \mathrm{g}$ \\
\cline { 2 - 9 } & 10 & 14 & 16 & 18 & 12 & 14 & 10 & 12 \\
\hline Amikacin $(30 \mu \mathrm{g})$ & \multicolumn{2}{|c|}{36} & \multicolumn{2}{|c|}{36} & \multicolumn{2}{|c|}{34} & 36
\end{tabular}

\section{Conclusions}

In conclusion, copper oxide nanoparticles were successfully synthesized using the aqueous leaf extracts of Leucas aspera and Morinda tinctoria plant material, which acted as reducing/stabilizing agents. The structure of the prepared nanoparticles was identified using XRD analysis. The specimen's shape and morphology were studied using SEM instrumentation and found to be spherical and cubical. The strong absorption peaks at $620 \mathrm{~cm}^{-1}$ and $615 \mathrm{~cm}^{-1}$ confirmed the formation of $\mathrm{CuO}$ nanoparticles. The optical band gap was calculated from the results of the UV-Vis spectrum. The prepared $\mathrm{CuO}$ nanoparticles' antibacterial activity was tested against a few Gram-negative and Gram-positive bacteria by disc diffusion method. The formed zone of inhibition was compared with the standard values of the reference sample Amikacin. Finally, the resulting green synthesis of $\mathrm{CuO}$ nanoparticles indicated appreciable antibacterial activity to find applications in medicine and food packaging. 


\section{Funding}

Author Dr. Ramesh expresses his gratitude to the management, Sacred Heart College, Tirupattur, for the Don Bosco Research Grant.

\section{Acknowledgments}

The authors extend their appreciation to the management, Sacred Heart College, Tirupattur, for constant support and encouragement.

\section{Conflicts of Interest}

All authors declare that there is no conflict of interest. The authors declare that they have no known competing financial interests or personal relationships that could have influenced the work reported in this paper.

\section{References}

1. Saravanakkumar, D.; Sivaranjani, S.; Kaviyarasu, K.; Ayeshamariam, A.; Ravikumar, B.; Pandiarajan, S.; Veeralakshmi, C.; Jayachandran, M.; Maaza, M. Synthesis and characterization of $\mathrm{ZnO}-\mathrm{CuO}$ nanocomposites powder by modified perfume spray pyrolysis method and its anti-microbial investigation. Journal of semiconductors 2018, 39, 033001, https://doi.org/10.1088/1674-4926/39/3/033001.

2. Nasrollahzadeh, M.; Sajadi, S.M.; Rostami-Vartooni, A.; Hussin, S.M. Green synthesis of CuO nanoparticles using aqueous extract of Thymus vulgaris $\mathrm{L}$. leaves and their catalytic performance for $\mathrm{N}$-arylation of indoles and amines. J. Colloid Interface Sci. 2016, 466, 113-119, https://doi.org/10.1016/j.jcis.2015.12.018.

3. Ren, G.; Hu, D.; Cheng, E.W.C.; Vargas-Reus, M.A.; Reip, P.; Allaker, R.P. Characterisation of copper oxide nanoparticles for anti-microbial applications. Int. J. Antimicrob. Agents 2009, 33, 587-590, https://doi.org/10.1016/j.ijantimicag.2008.12.004.

4. Gunalan, S.; Sivaraj, R.; Venckatesh, R. Aloe barbadensis Miller mediated green synthesis of mono-disperse copper oxide nanoparticles: Optical properties. Spectrochimica Acta Part A: Molecular and Biomolecular Spectroscopy 2012, 97, 1140-1144, https://doi.org/10.1016/j.saa.2012.07.096.

5. Zhang, Q.; Zhang, K.; Xu, D.; Yang, G.; Huang, H.; Nie, F.; Liu, C.; Yang, S. CuO nanostructures: Synthesis, characterization, growth mechanisms, fundamental properties, and applications. Prog. Mater Sci. 2014, 60, 208-337, https://doi.org/10.1016/j.pmatsci.2013.09.003.

6. Dhineshbabu, N.R.; Rajendran, V.; Nithyavathy, N.; Vetumperumal, R. Study of structural and optical properties of cupric oxide nanoparticles. Applied Nanoscience 2016, 6, 933-939, https://doi.org/10.1007/s13204-015-0499-2.

7. Francisco, M.S.P.; Mastelaro, V.R.; Nascente, P.A.P.; Florentino, A.O. Activity and Characterization by XPS, HR-TEM, Raman Spectroscopy, and BET Surface Area of CuO/CeO2-TiO2 Catalysts. The Journal of Physical Chemistry B 2001, 105, 10515-10522, https://doi.org/10.1021/jp0109675.

8. Fayaz, A.M.; Balaji, K.; Girilal, M.; Yadav, R.; Kalaichelvan, P.T.; Venketesan, R. Biogenic synthesis of silver nanoparticles and their synergistic effect with antibiotics: a study against gram-positive and gramnegative bacteria. Nanomed. Nanotechnol. Biol. Med. 2010, 6, 103-109, https://doi.org/10.1016/j.nano.2009.04.006.

9. Asemani, M.; Anarjan, N. Green synthesis of copper oxide nanoparticles using Juglans regia leaf extract and assessment of their physico-chemical and biological properties. Green Processing and Synthesis 2019, 8, 557-567, https://doi.org/10.1515/gps-2019-0025.

10. Ijaz, F.; Shahid, S.; Khan, S.A.; Ahmad, W.; Zaman, S. Green synthesis of copper oxide nanoparticles using Abutilon indicum leaf extract: Anti-microbial, antioxidant and photocatalytic dye degradation activitie. Tropical Journal of Pharmaceutical Research 2017, 16, 743-753, https://doi.org/10.4314/tjpr.v16i4.2.

11. Mohammadlou, M.; Jafarizadeh-Malmiri, H.; Maghsoudi, H. Hydrothermal green synthesis of silver nanoparticles using Pelargonium/Geranium leaf extract and evaluation of their antifungal activity. Green Processing and Synthesis 2017, 6, 31-42, https://doi.org/10.1515/gps-2016-0075. 
12. Manjari, G.; Saran, S.; Arun, T.; Vijaya Bhaskara Rao, A.; Devipriya, S.P. Catalytic and recyclability properties of phytogenic copper oxide nanoparticles derived from Aglaia elaeagnoidea flower extract. Journal of Saudi Chemical Society 2017, 21, 610-618, https://doi.org/10.1016/j.jscs.2017.02.004.

13. Peternela, J.; Silva, M.F.; Vieira, M.F.; Bergamasco, R.; Vieira, A.M.S. Synthesis and impregnation of copper oxide nanoparticles on activated carbon through green synthesis for water pollutant removal. Materials Research 2018, 21, https://doi.org/10.1590/1980-5373-mr-2016-0460.

14. Mohammad Shafiee, M.R.; Kargar, M.; Ghashang, M. Simple Synthesis of Copper Oxide Nanoparticles in the Presence of Extractive Rosmarinus Officinalis leaves. Journal of Nanostructures 2016, 6, 28-31, https://doi.org/10.7508/jns.2016.01.004.

15. Tamaekong, N.; Liewhiran, C.; Phanichphant, S. Synthesis of Thermally Spherical CuO Nanoparticles. Journal of Nanomaterials 2014, 2014, 507978, https://doi.org/10.1155/2014/507978.

16. Verma, N.; Kumar, N. Synthesis and Biomedical Applications of Copper Oxide Nanoparticles: An Expanding Horizon. ACS Biomaterials Science \& Engineering 2019, 5, 1170-1188, https://doi.org/10.1021/acsbiomaterials.8b01092.

17. Prasad, K.S.; Patra, A.; Shruthi, G.; Chandan, S. Aqueous Extract of $<\mathrm{i}>$ Saraca indica $</ \mathrm{i}>$ Leaves in the Synthesis of Copper Oxide Nanoparticles: Finding a Way towards Going Green. Journal of Nanotechnology 2017, 2017, 7502610, https://doi.org/10.1155/2017/7502610.

18. Singh, S.; Kumar, N.; Kumar, M.; Jyoti; Agarwal, A.; Mizaikoff, B. Electrochemical sensing and remediation of 4-nitrophenol using bio-synthesized copper oxide nanoparticles. Chem. Eng. J. 2017, 313, 283-292, https://doi.org/10.1016/j.cej.2016.12.049.

19. Balasubramanian, P.; Balamurugan, T.S.T.; Chen, S.-M.; Chen, T.-W. Facile Synthesis of Spinel-Type Copper Cobaltite Nanoplates for Enhanced Electrocatalytic Detection of Acetylcholine. ACS Sustainable Chemistry \& Engineering 2019, 7, 7642-7651, https://doi.org/10.1021/acssuschemeng.8b06021.

20. Sudha, V.; Krishnamoorthy, K.; Senthil Kumar, S.M.; Thangamuthu, R. Copper oxide nanosheet modified electrodes for simultaneous determination of environmentally hazardous anions. J. Alloys Compd. 2018, 764, 959-968, https://doi.org/10.1016/j.jallcom.2018.06.077.

21. Chung, I.M.; Abdul Rahuman, A.; Marimuthu, S.; Vishnu Kirthi, A.; Anbarasan, K.; Padmini, P.; Rajakumar, G. Green synthesis of copper nanoparticles using Eclipta prostrata leaves extract and their antioxidant and cytotoxic activities. Exp. Ther. Med. 2017, 14, 18-24, https://doi.org/10.3892/etm.2017.4466.

22. Vaidehi, D.; Bhuvaneshwari, V.; Bharathi, D.; Sheetal, B.P. Antibacterial and photocatalytic activity of copper oxide nanoparticles synthesized using Solanum lycopersicum leaf extract. Materials Research Express 2018, 5, 085403, https://doi.org/10.1088/2053-1591/aad426.

23. Rajendran, A.; Siva, E.; Dhanraj, C.; Senthilkumar, S. A green and facile approach for the synthesis copper oxide nanoparticles using Hibiscus rosa-sinensis flower extracts and it's antibacterial activities. J Bioprocess Biotech 2018, 8, 324, https://doi.org/10.4172/2155-9821.1000324.

24. Shabestarian, H.; Homayouni-Tabrizi, M.; Soltani, M.; Namvar, F.; Azizi, S.; Mohamad, R.; Shabestarian, H. Green synthesis of gold nanoparticles using sumac aqueous extract and their antioxidant activity. Materials Research 2017, 20, 264-270, http://dx.doi.org/10.1590/1980-5373-mr-2015-0694.

25. D.A. Jamdade, D. Rajpali, K.A. Joshi, R. Kitture, A.S. Kulkarni, V.S. Shinde, S. Ghosh, Gnidia glauca-and Plumbago zeylanica-Mediated Synthesis of Novel Copper Nanoparticles as Promising Antidiabetic Agents. Adv. Pharmacol. Sci. 2019, 2019, 9080279, https://doi.org/10.1155/2019/9080279.

26. Dadi, R.; Azouani, R.; Traore, M.; Mielcarek, C.; Kanaev, A. Antibacterial activity of $\mathrm{ZnO}$ and $\mathrm{CuO}$ nanoparticles against gram positive and gram negative strains. Materials Science and Engineering: C 2019, 104, 109968, https://doi.org/10.1016/j.msec.2019.109968.

27. Javed, R.; Ahmed, M.; Haq, I.u.; Nisa, S.; Zia, M. PVP and PEG doped CuO nanoparticles are more biologically active: Antibacterial, antioxidant, antidiabetic and cytotoxic perspective. Materials Science and Engineering: C 2017, 79, 108-115, https://doi.org/10.1016/j.msec.2017.05.006.

28. Katwal, R.; Kaur, H.; Sharma, G.; Naushad, M.; Pathania, D. Electrochemical synthesized copper oxide nanoparticles for enhanced photocatalytic and anti-microbial activity. Journal of Industrial and Engineering Chemistry 2015, 31, 173-184, https://doi.org/10.1016/j.jiec.2015.06.021.

29. Sathiyavimal, S.; Vasantharaj, S.; Bharathi, D.; Saravanan, M.; Manikandan, E.; Kumar, S.S.; Pugazhendhi, A. Biogenesis of copper oxide nanoparticles (CuONPs) using Sida acuta and their incorporation over cotton fabrics to prevent the pathogenicity of Gram negative and Gram positive bacteria. J. Photochem. Photobiol. B: Biol. 2018, 188, 126-134, https://doi.org/10.1016/j.jphotobiol.2018.09.014. 
30. Hosseini-Koupaei, M.; Shareghi, B.; Saboury, A.A.; Davar, F.; Sirotkin, V.A.; Hosseini-Koupaei, M.H.; Enteshari, Z. Catalytic activity, structure and stability of proteinase $\mathrm{K}$ in the presence of biosynthesized $\mathrm{CuO}$ nanoparticles. Int. J. Biol. Macromol. 2019, 122, 732-744, https://doi.org/10.1016/j.ijbiomac.2018.11.001.

31. Tavakoli, S.; Kharaziha, M.; Ahmadi, S. Green synthesis and morphology dependent antibacterial activity of copper oxide nanoparticles. Journal of Nanostructures 2019, 9, 163-171, https://doi.org/10.22052/JNS.2019.01.018.

32. Sivaraj, R.; Rahman, P.K.S.M.; Rajiv, P.; Narendhran, S.; Venckatesh, R. Biosynthesis and characterization of Acalypha indica mediated copper oxide nanoparticles and evaluation of its anti-microbial and anticancer activity. Spectrochimica Acta Part A: Molecular and Biomolecular Spectroscopy 2014, 129, 255-258, https://doi.org/10.1016/j.saa.2014.03.027

33. Gebremedhn, K.; Kahsay, M.H.; Aklilu, M. Green synthesis of $\mathrm{CuO}$ nanoparticles using leaf extract of catha edulis and its antibacterial activity. J. Pharm. Pharmacol 2019, 7, 327-342, https://doi.org/10.17265/23282150/2019.06.007.

34. Anand, G.T.; Nithiyavathi, R.; Ramesh, R.; John Sundaram, S.; Kaviyarasu, K. Structural and optical properties of nickel oxide nanoparticles: Investigation of anti-microbial applications. Surfaces and Interfaces 2020, 18, 100460, https://doi.org/10.1016/j.surfin.2020.100460.

35. Angeline Mary, A.P.; Thaminum Ansari, A.; Subramanian, R. Sugarcane juice mediated synthesis of copper oxide nanoparticles, characterization and their antibacterial activity. Journal of King Saud University Science 2019, 31, 1103-1114, https://doi.org/10.1016/j.jksus.2019.03.003.

36. Arunkumar, B.; Johnson Jeyakumar, S.; Jothibas, M. A sol-gel approach to the synthesis of CuO nanoparticles using Lantana camara leaf extract and their photo catalytic activity. Optik 2019, 183, 698-705, https://doi.org/10.1016/j.ijleo.2019.02.046. 